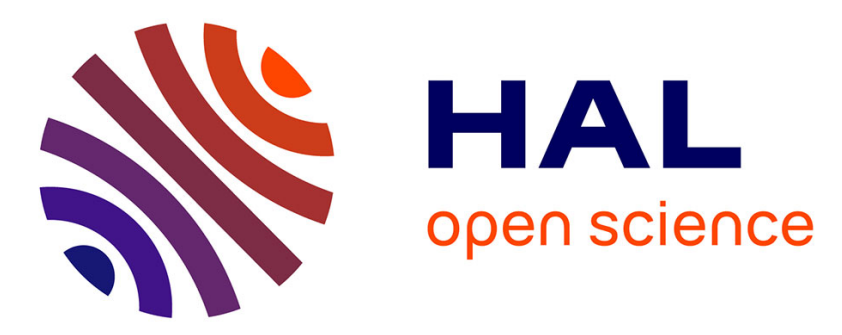

\title{
Acides gras polyinsaturés oméga 3 et toxicité hépatique de l'éthanol: rôle du remodelage membranaire
}

Odile Sergent, Normand Podechard, Fatiha Aliche-Djoudi, Dominique

Lagadic-Gossmann

\section{- To cite this version:}

Odile Sergent, Normand Podechard, Fatiha Aliche-Djoudi, Dominique Lagadic-Gossmann. Acides gras polyinsaturés oméga 3 et toxicité hépatique de l'éthanol : rôle du remodelage membranaire. Nutrition Clinique et Métabolisme, 2014, 28 (1), pp.17-28. 10.1016/j.nupar.2013.10.003 . hal-00966797

\section{HAL Id: hal-00966797 https://hal.science/hal-00966797}

Submitted on 27 Mar 2014

HAL is a multi-disciplinary open access archive for the deposit and dissemination of scientific research documents, whether they are published or not. The documents may come from teaching and research institutions in France or abroad, or from public or private research centers.
L'archive ouverte pluridisciplinaire HAL, est destinée au dépôt et à la diffusion de documents scientifiques de niveau recherche, publiés ou non, émanant des établissements d'enseignement et de recherche français ou étrangers, des laboratoires publics ou privés. 


\title{
Acides gras polyinsaturés oméga 3 et toxicité hépatique de l'éthanol : rôle du remodelage membranaire \\ Omega 3 polyunsaturated fatty acids and ethanol-induced liver toxicity : role of membrane remodeling
}

\author{
Odile Sergent $^{1,2}$, Normand Podechard ${ }^{1,2}$, Fatiha Aliche-Djoudi ${ }^{1,2}$, \\ Dominique Lagadic-Gossmann ${ }^{1,2}$
}

\footnotetext{
1 : UMR Inserm 1085, IRSET, UFR des Sciences Pharmaceutiques et Biologiques, 2, av Pr Léon Bernard, 35043 Rennes cédex, France

2 : Université de Rennes 1, Biosit UMS3080, 2, av Pr Léon Bernard, 35043 Rennes cédex, France
}

\section{Correspondant :}

Odile Sergent

Tél : 0223234808

Fax : 0223234794

e-mail : osergent@univ-rennes1.fr

\section{Remerciements :}

Les auteurs souhaitent remercier l'IREB (Institut de Recherche Scientifiques sur les Boissons, Paris, France) pour son soutien financier. Ils remercient également la région Bretagne qui a accordé une bourse de thèse à Fatiha Aliche-Djoudi. Ils sont également très reconnaissants à Martine Chevanne pour son assistance technique. L'union européenne (FEDER), la Région Bretagne, le Conseil Général d'Ille-etVilaine, Rennes Métropole et le Ministère de l'Enseignement Supérieur et de la 
Recherche (MESR) sont aussi remerciés pour leur aide financière du projet Membratox (Contract number 32508, 350 keuros).

Titre courant :

Oméga 3 et radeaux lipidiques 


\section{Résumé :}

La maladie alcoolique du foie se caractérise par une stéatose précoce, qui, pour seulement $20 \%$ des buveurs excessifs, peut évoluer vers la stéatohépatite ou la cirrhose. A l'heure actuelle, la description des facteurs de risque et des mécanismes cellulaires et moléculaires impliqués dans la progression de la maladie restent toujours incomplète. Ces dernières années, les radeaux lipidiques, microstructures de la membrane plasmique, ont été décrits comme une nouvelle cible de l'exposition à l'éthanol. Or, les acides gras polyinsaturés oméga 3, présents naturellement dans certains aliments comme les poissons gras, se sont révélés être capables de modifier le microenvironnement physicochimique de ces microstructures avec des effets bénéfiques pour certaines pathologies comme l'inflammation ou le cancer. L'objectif de cette revue est ainsi d'établir un lien entre les altérations membranaires induites par les oméga 3 et leurs effets sur les mécanismes moléculaires impliqués dans la progression de la maladie alcoolique du foie.

\section{Mots-clefs :}

Radeaux lipidiques ; membranes ; mort cellulaire ; stress oxydant ; stéatose 


\begin{abstract}
:
Alcoholic liver disease is characterized by an early development of steatosis, that can progress to steatohepatitis or cirrhosis, but only for $20 \%$ of heavy drinkers. Nowadays, description of risk factors and of cellular and molecular mechanisms involved in the disease pathogenesis still remains incomplete. These last years, the plasma membrane microstructures called lipid rafts, were described as a new target for ethanol. Besides, n-3 polyunsaturated fatty acids, naturally present in fat fish, were reported to be able to modulate physically and chemically the lipid raft microenvironment, with beneficial effects towards inflammation or cancer. In this context, the aim of the present review was to establish a link between omega 3induced membrane alterations and their effects on the molecular mechanisms involved in alcoholic liver disease pathogenesis.
\end{abstract}

\title{
Keywords :
}

Lipid rafts ; membranes ; cell death ; oxidative stress ; steatosis 
La consommation excessive d'alcool (éthanol) peut conduire à des dommages hépatiques dont la progression dépend de la fréquence, la durée de cette consommation ainsi que de la dose d'éthanol [1]. La maladie alcoolique du foie se caractérise par le développement précoce d'une stéatose, qui peut évoluer vers la stéatohépatite, la fibrose et cirrhose et parfois dégénérer en un carcinome hépatocellulaire [2]. La stéatose, appelée aussi "foie gras", première étape de la maladie est détectée chez $90 \%$ environ des consommateurs excessifs d'alcool [3, 4]. Réversible et bénigne, elle se caractérise par l'accumulation anormale de lipides dans les hépatocytes. L'hépatite, étape suivante, se distingue par l'inflammation et la mort des hépatocytes. Si elle est également réversible à ses débuts, la poursuite de l'intoxication peut conduire à des formes sévères et irréversibles avec des taux de mortalité de 30 à $60 \%$ [5]. La progression de la maladie entraîne l'activation des cellules étoilées du foie avec l'accumulation d'un excès de matrice extracellulaire (fibrose) suivi d'un remodelage irréversible de l'architecture du foie avec formation de nodules anormaux et destruction des sinusoides hépatiques (cirrhose) [6]. Cependant, la consommation excessive d'alcool entraîne l'évolution vers une forme sévère de la maladie alcoolique du foie (hépatite/cirrhose) chez seulement $20 \%$ des malades alcooliques [3, 4] (Figure 1). Ainsi, chez ces derniers, des facteurs additionnels (style de vie et/ou co-morbidités) [1, 3, 7], des prédispositions génétiques [8] ou le "binge drinking" (hyperalcoolisation sur une courte période de temps) [9] ont été proposés comme causes possibles de cette évolution. Une hypothèse nommée "Second hit hypothesis" a aussi été émise à propos de la progression non systématique de la maladie alcoolique du foie vers les formes sévères (Figure 1). Elle met en jeu une première agression ("First hit") liée à la prise excessive d'alcool qui se traduit par le développement de la stéatose [10]. Bien que 
bénigne, elle sensibilise le foie à des agressions ultérieures ("Second hits") dues à la fois à l'exposition continue à l'éthanol et à des conditions défavorables d'ordre nutritionnel (obésité, nature des régimes alimentaires), pharmacologique (prise de médicaments concomitante), infectieuse (hépatites virales), environnementale (tabac) ou génétique [11]. Cependant, malgré le développement de nombreux modèles d'étude [11], la description de ces facteurs de risque et des mécanismes cellulaires et moléculaires impliqués dans la progression de la maladie reste toujours incomplète.

Ces dernières années, les radeaux lipidiques, microstructures de la membrane plasmique, ont été décrits comme une nouvelle cible de l'exposition à l'éthanol [12, 13]. Parallèlement, les acides gras polyinsaturés oméga 3, présents naturellement dans certains aliments comme les poissons gras, se sont révélés être capables de modifier le microenvironnement physicochimique de ces microstructures avec des effets bénéfiques pour certaines pathologies comme l'inflammation [14] ou le cancer [15]. L'objectif de cette revue est ainsi d'établir un lien entre les effets membranaires des acides gras polyinsaturés oméga 3 et leur impact sur les mécanismes moléculaires impliqués dans les différentes étapes de la progression de la maladie alcoolique du foie. Les aspects nutritionnels faisant partie des facteurs de risque, cette revue devrait permettre de définir les bases moléculaires et cellulaires de régimes à risque ou bénéfiques face à la progression de cette maladie.

\section{Toxicité de l'éthanol}

\section{Les mécanismes cellulaires et moléculaires classiques de la toxicité de} l'éthanol

Les mécanismes cellulaires et moléculaires de la progression de la maladie alcoolique du foie sont nombreux et non encore totalement compris. Parmi ceux-ci, 
le métabolisme de l'éthanol tient une place importante car il participe au développement d'évènements importants dans la progression de la maladie notamment le stress oxydant, l'inflammation et le dépôt excessif de matrice extracellulaire.

\subsection{Influence du métabolisme de l'éthanol sur la stéatose et le stress oxydant}

Le foie étant le principal organe responsable du métabolisme de l'éthanol, il est donc très sensible à la toxicité de cette molécule. Les cellules concernées sont essentiellement les hépatocytes, mais les cellules de Küpffer (macrophages résidents du foie) peuvent aussi participer à ce métabolisme [16].

L'alcool est métabolisé en acétaldéhyde par 3 voies oxydatives principales : la voie de l'alcool déshydrogénase (ADH) dans le cytosol, la voie du système microsomal de l'éthanol (MEOS) impliquant le cytochrome P4502E1 dans le réticulum endoplasmique et enfin une voie mineure, celle de la catalase dans le peroxysome (Figure 2). La voie de l'ADH est responsable de la majeure partie du métabolisme lorsque les concentrations sanguines en éthanol sont faibles $(0,2$ à $2 \mathrm{mM})$ [5]. Pour de plus fortes concentrations (10-15 mM), le métabolisme s'effectue par la voie du MEOS. Il s'agit d'une voie inductible [17]. L'acétaldéhyde est ensuite pris en charge par l'aldéhyde déshydrogénase (ALDH) mitochondriale pour former de l'acétate, qui n'étant pratiquement pas métabolisé dans le foie, passe dans la circulation générale pour être finalement dégradé en $\mathrm{CO}_{2}$ principalement dans les autres tissus. L'oxydation par l'ADH et l'ALDH entraîne la réduction du nicotinamide adénine dinucléotide oxydé (NAD) en nicotinamide adénine dinucléotide réduit (NADH). Ce métabolisme entraîne des effets toxiques (Figure 3) principalement par : 
(1) la production de l'acétaldéhyde qui est très réactif et forme des adduits avec les protéines et l'ADN. Ces adduits sont responsables de réactions inflammatoires et immunes [18]. L'acétaldéhyde stimule également la production de collagène par les cellules étoilées du foie [19]. Il entraîne aussi un dysfonctionnement mitochondrial et participe à l'induction du stress oxydant [20]. L'acétaldéhyde inhibe aussi l'activation d'un facteur de transcription dont les gènes sous contrôle interviennent dans la beta oxydation des acides gras, à savoir le PPAR $\alpha$ (peroxisome proliferator-activated receptor de type alpha) [21] ; ce même métabolite est également connu pour activer un autre facteur de transcription, le SREBP-1 (sterol regulatory element-binding protein de type 1), intervenant dans la lipogenèse. L'ensemble de ces effets favorise le développement de la stéatose;

(2) une élévation du rapport NADH/NAD, qui modifie de nombreuses voies métaboliques conduisant à une perturbation du métabolisme des glucides et des lipides (stéatose) [1];

(3) les espèces réactives de l'oxygène, espèces très oxydantes pour certaines, produites directement par le cytochrome P4502E1, et indirectement par l'élévation du rapport NADH/NAD [20, 22]. Ceci conduit au développement d'un stress oxydant. Le stress oxydant a pour origine un déséquilibre entre les facteurs prooxydants et les systèmes antioxydants en faveur des premiers, ce qui déclenche des dommages oxydatifs des biomolécules et une altération de la signalisation redox. Il joue un rôle particulièrement important dans la pathogénèse de la maladie alcoolique $[17,18,20]$.

\subsection{Inflammation et mort cellulaire, caractéristiques de la stéatohépatite}

L'inflammation et la mort cellulaire sont des caractéristiques de la progression de la maladie hépatique vers la stéatohépatite. Cette inflammation consiste en une 
augmentation des taux de cytokines, une activation de cellules immunitaires (macrophages résidents du foie [cellules de Küpffer], lymphocytes NK [Natural Killer] et lymphocytes $\mathrm{T}$ ) et un recrutement de neutrophiles/monocytes dans le foie. Les acteurs de promotion de l'inflammation par l'éthanol sont nombreux [23].

\subsubsection{Le lipopolysaccharide}

Le lipopolysaccharide (LPS), constituant de la paroi cellulaire des bactéries gram négatif de la flore intestinale, est un des inducteurs d'inflammation le mieux connu dans la pathogénèse de la maladie alcoolique [23]. La consommation chronique d'éthanol entraîne la prolifération de la flore intestinale associée à une augmentation de la perméabilité intestinale, avec pour conséquence l'entrée de LPS dans la circulation générale (Figure 4). Le LPS est reconnu par le récepteur TLR4 (Toll-like receptor de type 4), présent à la membrane plasmique des cellules de Küpffer et des hépatocytes [24]. La liaison du LPS aux cellules de Küpffer entraîne leur stimulation pour la production de cytokines proinflammatoires (tumor necrosis factor alpha [TNF $\alpha$; interleukine 1 [IL1]; interleukine 6 [IL6]), de chimiokines ou encore de l'anion superoxyde via l'activation de la NADPH oxydase $[25,26]$. La production de cytokines proinflammatoires peut ensuite agresser les hépatocytes déclenchant la mort de ceux-ci; les chimokines favorisent le recrutement de cellules inflammatoires comme les neutrophiles/monocytes accentuant alors l'inflammation; enfin, la production d'espèces réactives de l'oxygène entretient le stress oxydant dans le foie.

\subsubsection{Les produits du métabolisme de l'éthanol}

Les espèces réactives de l'oxygène peuvent entraîner l'activation de la signalisation cellulaire dépendante du facteur de transcription NF- $\mathrm{B}$ (nuclear factor-kappa B), 
avec notamment l'expression de cytokines proinflammatoires et de chimiokines [23] (Figure 5). En outre, des adduits aux protéines peuvent se former à partir des aldéhydes produits par la peroxydation lipidique, du radical hydroxyéthyle (radical libre issu de l'attaque radicalaire de l'éthanol) et/ou de l'acétaldéhyde [27, 28]. Ces adduits peuvent déclencher des réponses inflammatoires de la part des cellules de Küpffer et des cellules endothéliales des sinusoides hépatiques [29, 30]. Ils peuvent également se comporter comme des antigènes induisant des réponses immunitaires avec production d'anticorps et activation des lymphocytes $\mathrm{T}$ cytotoxiques, et des réactions inflammatoires secondaires $[28,30]$. Dans ce processus, les cellules de Küpffer se comportent comme des cellules présentant l'antigène aux lymphocytes [31].

\subsubsection{L'hypoxie}

L'hypoxie est liée à la forte consommation en oxygène due au métabolisme de l'éthanol. L'hypoxie entraîne l'activation d'un facteur de transcription HIF (HypoxiaInducible Factor 1 alpha) qui coopère avec le facteur de transcription NF-kB pour induire la production de cytokines proinflammatoires et de chimiokines [23]. Les cytokines proinflammatoires associées au stress oxydant peuvent ensuite déclencher la mort des hépatocytes [23].

\subsection{Fibrose}

L'activation des cellules étoilées entraînant une augmentation d'expression $\mathrm{du}$ collagène est une caractéristique de la progression de la maladie vers la fibrose. En effet, la fibrose se définit par un excès de dépôt de matrice extracellulaire. La production de cytokines proinflammatoires, d'espèces réactives de l'oxygène et de 
l'azote, ainsi que la libération de corps apoptotiques sont des acteurs essentiels au développement de la fibrose [32]. Chacun d'eux est produit au cours des étapes précédentes de la maladie alcoolique. Les cellules de Küpffer activées peuvent aussi libérer des cytokines de type TGF (Transforming Growth Factor beta) capables d'activer les cellules étoilées [2]. En outre, l'acétaldéhyde, les espèces réactives de l'oxygène, le lipopolysaccharide et les adduits aux protéines décrits ci-dessus peuvent aussi activer ces cellules $[6,33,34]$. Enfin, les cellules étoilées activées peuvent aussi produire des espèces réactives de l'oxygène par activation de la NADPH oxydase, entretenant ainsi le stress oxydant [25], et propager l'inflammation en libérant cytokines et chimiokines [6]. Par ailleurs, les lymphocytes résidents NK qui ont pour fonction de bloquer l'activation des cellules étoilées sont inactivés par l'intoxication chronique par l'éthanol [35].

\section{Rôle des radeaux lipidiques dans la toxicité hépatique de l'éthanol}

En raison de l'effet bien connu de l'éthanol sur la fluidité de la membrane plasmique [13], les chercheurs s'intéressent depuis le début des années 2000 à une implication éventuelle des radeaux lipidiques dans le développement des maladies alcooliques. En effet, les lipides de la membrane plasmique ne sont plus considérés comme répartis au hasard dans la bicouche lipidique mais plutôt de façon sélective en fonction des propriétés d'auto-association entre le cholestérol et les sphingolipides. Ainsi les radeaux lipidiques représentent des microstructures de la membrane plasmique enrichies en cholestérol, sphingolipides, et phospholipides à acides gras saturés, ce qui rend ces microdomaines plus compacts et plus rigides que les autres régions de la membrane plasmique constituées essentiellement par des phospholipides à acides gras polyinsaturés [36, 37] (Figure 6). Les radeaux lipidiques 
peuvent contenir des protéines spécifiques en fonction de leur affinité pour certains lipides [38] ou de leur ancrage par des acides gras saturés [39]. Parmi ces protéines, on peut citer des protéines à ancre glycosylphosphatidylinositol (GPI), des récepteurs comme les récepteurs de mort, les "Toll-Like Récepteurs" (TLR) ou des protéines de signalisation comme des "Mitogen Activated Protein" (MAP) kinases, protéine kinases $\mathrm{C}$, etc. Certaines sont résidentes et d'autres sont recrutées dans les radeaux après activation cellulaire. Les radeaux lipidiques, microstructures extrêmement dynamiques de 1 à $10 \mathrm{~nm}$, peuvent migrer et se rassembler dans la membrane plasmique, regroupant ainsi plusieurs protéines sur un même site pour constituer des plateformes de signalisation (à l'échelle du $\mu \mathrm{m}$ ), qui activent ou inhibent différentes voies de signalisation [40-42] (Figure 6). Ces plate-formes peuvent se constituer suite à la liaison d'un ligand à son récepteur.

L'implication des radeaux lipidiques dans la toxicité de l'éthanol a ainsi été démontrée essentiellement pour deux voies de signalisation : l'une porte sur l'immunité innée par perturbation de la voie de signalisation TLR4 dépendante et l'autre sur la mort des hépatocytes par activation de la voie de signalisation phospholipase $\mathrm{C}$ dépendante.

\subsection{Implication des radeaux lipidiques dans le développement de l'inflammation}

Le développement des maladies alcooliques du foie fait intervenir les acteurs de l'immunité innée, en particulier les macrophages et les cellules de Küpffer (Cf paragraphe I.2). Ainsi, ces cellules répondent à la stimulation du récepteur TLR4 par le LPS en produisant des cytokines, chimiokines et des espèces réactives de l'oxygène (ERO). Ce récepteur est également présent à la surface des hépatocytes et des cellules étoilées [24] si bien que son activation est fondamentale dans le 
développement des maladies alcooliques du foie [35]. Pour son activité, le TLR4 doit être transloqué dans les radeaux lipidiques où il s'associe à un co-récepteur, le CD14, déjà présent de manière constitutive dans les radeaux lipidiques. Le CD14 est le véritable récepteur du LPS, mais ne disposant pas de domaine cytoplasmique, il transmet le signal d'activation au TLR4 qui transduit alors le signal au travers de la membrane plasmique $[40,43,44]$. L'activation par le LPS entraîne une modification du profil de distribution du CD14 dans les radeaux lipidiques [45]. En fonction de la concentration, l'éthanol entraîne des altérations différentes de la signalisation dépendante des radeaux lipidiques [13]. A forte concentration (> $50 \mathrm{mM}$ ), dans les macrophages RAW [46, 47], les macrophages péritonéaux [47], les monocytes humains [45], l'éthanol empêche la translocation de TLR4 dans les radeaux ainsi que la redistribution du CD14 dans ces mêmes radeaux avec pour conséquence une diminution de la production de cytokines proinflammatoires (TNF $\alpha)$. Selon les auteurs, ceci pourrait expliquer en partie que la consommation d'éthanol est un facteur de risque pour des infections concomitantes. En effet, le TNF $\alpha$ est une cytokine-clef dans la défense de l'hôte contre les infections bactériennes, fongiques ou virales $[48,49]$. Pour des concentrations plus faibles (10 mM), l'éthanol présente un effet inverse c'est-à-dire une stimulation de la translocation de TLR4 dans les radeaux lipidiques avec une production augmentée de cytokines proinflammatoires $(\mathrm{TNF} \alpha)$ [47] ce qui laisse supposer que les radeaux lipidiques seraient impliqués dans les mécanismes de développement de l'inflammation dans les maladies alcooliques du foie.

\subsection{Implication des radeaux lipidiques dans l'induction du stress oxydant et la mort des hépatocytes}


Notre équipe a montré que les radeaux lipidiques participent au développement du stress oxydant induit par l'éthanol dans des hépatocytes de rat en culture primaire [50]. Ainsi, le métabolisme de l'éthanol en produisant des espèces réactives de l'oxygène à faible niveau entraîne des modifications oxydatives des radeaux lipidiques provoquant l'agrégation de ceux-ci (Figure 6). En effet, la production d'espèces réactives de l'oxygène peut oxyder des groupements thiols de protéines avec formation de ponts disulfures entre protéines de radeaux différents, rapprochant alors ceux-ci (Figure 6). En outre, les aldéhydes issus de la peroxydation lipidique, notamment le malondialdéhyde et le 4-hydroxynonenal, peuvent réagir avec les lysines, les histidines ou les cystéines des protéines produisant des groupements carbonyles $(\mathrm{CHO})$ dans certains radeaux. Ces groupements peuvent former des bases de Schiff $(-\mathrm{CH}=\mathrm{N}-)$ avec des groupements aminés de protéines présentes dans d'autres radeaux, conduisant à l'agrégation des radeaux. Cette agrégation est responsable de la translocation et de l'activation de la phospholipase $\mathrm{C}$ qui secondairement provoque un stress oxydant beaucoup plus important aboutissant en final à la mort des hépatocytes. Par la suite, nous avons également montré que l'activation de la phospholipase $\mathrm{C}$ est en fait impliquée dans l'augmentation du nombre des lysosomes, principale source de fer libre, un facteur particulièrement oxydant [51].

\section{Effet des oméga 3 sur la toxicité hépatique de l'éthanol}

Si l'on considère des modèles in vivo sur rongeurs, les effets bénéfiques des acides gras polyinsaturés vis-à-vis des maladies du foie non alcooliques s'accumulent. Ainsi, ils peuvent protéger de la stéatose, du stress oxydant, de l'inflammation et de la fibrose hépatique [52, 53]. En outre, de nombreuses études montrent aussi une 
réduction de la stéatose non alcoolique chez l'homme, mais les effets sur les autres caractéristiques histopathologiques de la stéatohépatite ne sont pas encore bien connus [53-55]. A l'inverse, les résultats demeurent controversés en ce qui concerne la maladie alcoolique du foie.

\section{Augmentation de la toxicité hépatique de l'éthanol}

Dans les années 80, des études épidémiologiques ont montré la corrélation entre la nature des régimes alimentaires des individus et l'avancée de la maladie alcoolique. Ainsi, des régimes enrichis en acides gras saturés et cholestérol protègent de la cirrhose alcoolique à l'inverse de ceux à plus forte teneur en acides gras polyinsaturés [56]. Puis dans des modèles de rongeurs, il a été établi que les régimes à base d'huile de mais (57\% acide linoléique, acide gras polyinsaturé n-6 [C18:2, n-6]), entraînent des altérations hépatiques plus importantes que les régimes à base de graisse animale (2,5\% acide linoléique) [57]. Enfin, en apportant un régime à base d'huile de poisson, les effets des acides gras polyinsaturés n-3 se révèlent encore plus toxiques avec une augmentation de la sévérité des dommages hépatiques par rapport au régime à base d'huile de maïs $[58,59]$. Ceux-ci se caractérisent par une augmentation de la stéatose, des foyers nécrotiques et inflammatoires [60]. Les mécanismes de cette toxicité font intervenir le développement d'un stress oxydant et d'une inflammation.

\subsection{Stress oxydant}

L'administration d'huile de poisson à des rongeurs entraîne une augmentation de la peroxydation lipidique induite par l'éthanol dans le foie par rapport à des régimes à base d'huile de maïs [58-61]. La sévérité des dommages hépatiques est corrélée à 
l'augmentation de la peroxydation lipidique due à ce régime particulier [59, 62]. Selon Nieto [63], la peroxydation lipidique est directement impliquée dans le mécanisme de dépôt de collagène et de déclenchement de la fibrose. En parallèle, une

diminution de l'activité d'enzymes antioxydantes (glutathion peroxydase, $\mathrm{Cu}, \mathrm{Zn}$ superoxyde dismutase et catalase) est observée, mais elle n'est pas plus importante que celle détectée suite à des régimes à base d'huile de maïs, sauf pour la glutathion peroxydase [61]. Dans le groupe "huile de poisson et éthanol", l'induction de l'expression des ARNm de la glutathion peroxydase et de la catalase est la plus forte [64]. Ceci peut s'expliquer par une adaptation à un stress oxydant plus important. L'induction plus importante du cytochrome P4502E1, également retrouvée dans les groupes de rongeurs soumis au régime "huile de poisson" [59, 63] pourrait aussi expliquer l'augmentation du stress oxydant. Enfin, une plus forte inhibition de l'activité du protéasome, complexe protéique dégradant les protéines oxydées, a aussi été observée [62].

\subsection{Inflammation}

Une augmentation des taux circulants de lipopolysaccharides fait partie des mécanismes de déclenchement de l'inflammation dans la maladie alcoolique du foie (cf paragraphe I.2.1). Dans le foie de rat traité par l'éthanol, le récepteur CD14 de ce lipopolysaccharide présente une augmentation de son expression en ARNm et protéine sous l'influence d'un régime à base d'huile de poisson [65]. Parmi les différents types cellulaires du foie, seuls les hépatocytes présentent une augmentation d'expression significative de ce récepteur si on compare les régimes huile de maïs et huile de poisson [65]. L'infiltration du foie par des cellules inflammatoires est aussi la plus forte dans le groupe "huile de poisson" [65]. Ceci peut s'expliquer par une 
augmentation de l'activité du facteur de transcription NF-кB [66], dont les gènes sous contrôle contribuent au développement de l'inflammation et dont l'activité dépend de la production des espèces réactives de l'oxygène (cf paragraphe I.1.2.2). Ainsi, chez les rats alcoolisés, le régime à base d'huile de poisson entraîne une augmentation de l'expression hépatique de cytokines et eicosanoides proinflammatoires, de chimiokines et une diminution des cytokines anti-inflammatoires par rapport au régime "huile de maïs" [66, 67].

\section{Protection de la toxicité hépatique de l'éthanol}

Plus récemment, différentes études montrent un rôle protecteur de l'huile de poisson ou du DHA vis-à-vis de la stéatose et de la nécrose induite par l'éthanol chez les rongeurs soumis à une intoxication aigüe ou chronique [68-70]. Plusieurs mécanismes ont été décrits faisant intervenir un effet sur la lipogenèse, le stress oxydant et l'inflammation.

\subsection{Lipogenèse}

Le régime à base d'huile de poisson réduit l'expression de facteurs de transcription impliqués dans la lipogenèse comme SREBP-1 et augmente celle de facteurs impliqués dans la lipolyse comme PPAR $\alpha$ [68]. Ainsi, l'expression de gènes impliqués dans la lipogenèse comme l'acétyl-CoA carboxylase est réduite [69]. Or une augmentation de l'activité d'une enzyme du métabolisme de l'éthanol, l'ALDH, est aussi observée, ce qui favorise l'élimination de l'acétaldéhyde métabolite fortement impliqué dans l'induction de la stéatose par l'éthanol (cf paragraphe I.1) [69]. 


\subsection{Stress oxydant}

Le DHA protège de la peroxydation lipidique induite par l'éthanol dans le foie [69]. Ceci serait lié au rétablissement d'un fonctionnement mitochondrial normal ayant pour conséquence une diminution de la production des espèces réactives de l'oxygène à partir des mitochondries [69]. En outre, une diminution de la production d'espèces oxydantes pourrait être attribuée à la diminution de l'expression et de l'activité du cytochrome P4502E1 ainsi que de la monoxyde d'azote synthase inductible [69]. Une élévation de l'expression de l'hème oxygénase, enzyme antioxydante, est aussi détectée dans le foie de rats alcoolisés et traités par le DHA [70].

\subsection{Inflammation}

Le DHA peut aussi réduire les taux de cytokines proinflammatoires dans le foie [70].

3. Rôle des radeaux lipidiques dans les effets des acides gras polyinsaturés oméga 3

Au vu de la littérature, l'effet des acides gras polyinsaturés n-3 ne semble donc pas clair. Une tentative d'explication peut être envisagée si on considère maintenant leurs effets sur les radeaux lipidiques.

\subsection{Modulation des propriétés physicochimiques des radeaux lipidiques par les} acides gras polyinsaturés oméga 3

Il est possible de modifier les propriétés physicochimiques des radeaux lipidiques grâce aux nutriments, notamment les flavonoides extraits des plantes [71] ou les acides gras polyinsaturés provenant des poissons gras [72]. Sont particulièrement intéressants les acides gras polyinsaturés oméga 3 à longue chaîne, comme l'acide 
eicosapentaénoïque (C20:5) et l'acide docosahexaénoïque (C22:6). Ces deux acides gras se caractérisent par leur longue chaîne carbonée à 20 et 22 carbones, respectivement, et leur forte insaturation ( 5 et 6 double liaisons, respectivement). A l'inverse des quelques tissus comme le cerveau contenant de fortes concentrations d'oméga 3 (DHA) dans leurs membranes, la plupart des tissus en contiennent moins de $10 \%$ mais sont beaucoup plus sensibles à un apport nutritionnel notamment le foie dont les taux augmentent le plus (jusqu'à 12 fois) [73, 74].

Les acides gras polyinsaturés n-3 à longue chaîne en modulant les caractéristiques physicochimiques des radeaux lipidiques peuvent modifier différentes voies de signalisation dépendantes de ces microdomaines comme celles impliquées dans la réponse immune des lymphocytes $\mathrm{T}[75,76]$, la prolifération cellulaire de cellules de cancer du sein, du poumon ou du colon [15], l'inflammation dans les cellules endothéliales des vaisseaux rétiniens [77] et les lymphocytes [78]. En outre, ces mêmes effets sont retrouvés in vivo après administration d'huile de poisson à des rongeurs. Ainsi, ce type de régime en modifiant les propriétés physicochimiques des radeaux est capable d'interférer avec la réponse inflammatoire des lymphocytes $\mathrm{T}$ [79] et des lymphocytes B [80], celles déclenchée par l'ischémie-reperfusion dans le foie [81], ou par l'induction expérimentale d'une colite [82]. Ces changements dans la signalisation cellulaire sont dus essentiellement à des mouvements de protéines clefs de la signalisation cellulaire vers ou hors les radeaux lipidiques entraînant leur inhibition ou activation. Peuvent être citées les protéines de signalisation suivantes : tyrosine kinases, protéine kinases C, récepteur de l'interleukine 2 (IL2R), récepteur Toll Like (TLR4), récepteur du facteur de croissance épidermique (EGFR), phospholipase $\mathrm{D}$, etc. 
Il est possible de décrire deux types de modifications physicochimiques des radeaux lipidiques sous l'influence des acides gras polyinsaturés n-3 expliquant des mouvements de protéines de signalisation et la modification d'activité des voies en dépendant.

\subsubsection{Augmentation de l'agrégation des radeaux lipidiques}

En raison de leur grande flexibilité, ces acides gras et notamment le DHA, sont décrits dans les membranes artificielles pour présenter une forte incompatibilité stérique avec le cholestérol et les sphingolipides ce qui accentue la séparation de phase de ces membranes entre régions radeaux plus rigides et régions non radeaux plus fluides [72, 83]. Ainsi, dans les hépatocytes, nous avons montré que l'EPA s'insère préférentiellement dans les régions non radeaux et que les molécules de cholestérol présentes dans ces régions en sont alors exclues pour rejoindre les radeaux lipidiques augmentant ainsi la formation de ceux-ci et provoquant leur agrégation [51] (Figure 7). Ces mouvements sont accentués par l'augmentation de fluidité des membranes sous l'effet de l'EPA [51]. On peut supposer que cette agrégation puisse permettre la formation de plateforme de signalisation et le recrutement de nouvelles protéines de signalisation (Cf ci-dessous).

\subsubsection{Formation de régions non radeaux dans les radeaux}

Par des méthodes d'imagerie quantitative, il a été montré que le DHA empêche l'agrégation des radeaux en s'insérant dans ceux-ci in vitro, notamment dans les lymphocytes EL4 $[84,85]$ et in vivo dans les lymphocytes B isolés de souris nourries par des régimes à base d'huile de poisson [85]. Ceci peut s'expliquer par les propriétés biophysiques du DHA: par sa très grande flexibilité, il est capable de 
s'insérer dans les radeaux lipidiques ; toutefois par son incompatibilité stérique avec le cholestérol, il entraîne la formation de régions non radeaux de taille nanométrique dans les radeaux [86] augmentant ainsi la taille de ceux-ci [84, 85] (Figure 7). De ce fait, les interactions protéine-protéine n'ont plus lieu et les voies de signalisation radeaux dépendantes sont inhibées.

\subsubsection{Effets différentiels de l'EPA et du DHA}

A l'heure actuelle, l'EPA et le DHA sont de plus en plus décrits comme se comportant différemment vis-à-vis des radeaux lipidiques. Ainsi, le DHA, mais pas l'EPA, inhibe l'agrégation des radeaux lipidiques dans les lymphocytes EL4 [84, 85]. Seul le DHA provoque l'augmentation de taille des radeaux lipidiques. En outre, il a été montré que le DHA s'incorpore mieux dans les radeaux à la fois dans des modèles cellulaires [80] et dans des modèles de membranes artificielles [87].

$\mathrm{Au}$ total, on peut donc penser que les acides gras polyinsaturés oméga 3, en altérant la structure des radeaux, peuvent avoir une influence sur la toxicité hépatique de l'éthanol.

\subsection{Implication des radeaux lipidiques dans les effets des oméga 3 sur la toxicité} hépatique de l'éthanol

Dans les hépatocytes de rat en culture primaire, nous avons montré que l'EPA est capable de provoquer un stress structural de la membrane plasmique entraînant l'agrégation des radeaux lipidiques [50]. Ceci accentue l'agrégation induite par l'éthanol et la toxicité dépendante des radeaux. Ainsi, la translocation de la phospholipase C induite par l'éthanol est largement augmentée sous l'effet de l'EPA avec pour conséquences une élévation considérable des taux de fer libre et du stress 
oxydant [50]. Cependant, il faut souligner que le DHA par ses capacités d'incorporation dans les radeaux lipidiques, est capable d'inhiber l'agrégation des radeaux lipidiques (cf paragraphe 3.1.2). On peut donc supposer que par ses effets opposés à l'EPA (cf paragraphe 3.1.3), le DHA peut protéger de la toxicité de l'éthanol dépendant des radeaux lipidiques [88]. Or, lorsque l'on compare la composition en EPA/DHA des huiles de poisson testées vis-à-vis de l'intoxication hépatique de l'éthanol chez le rongeur, on constate que les huiles ayant apporté une protection sont plus riches en DHA.

\section{Conclusion}

D'après cette revue de littérature, concernant les acides gras polyinsaturés oméga 3 , il semble donc difficile à l'heure actuelle de définir des régimes à risque ou bénéfique dans le cadre de l'intoxication hépatique par l'alcool. Cependant, dans l'état actuel de nos connaissances, des précautions quant à l'utilisation des compléments alimentaires à base d'oméga 3 semblent indispensables dans le contexte de l'intoxication hépatique par l'alcool. Des études complémentaires concernant les effets différentiels de l'EPA et du DHA apporteront certainement des réponses, notamment par le biais d'expérimentations in vitro à plus long terme ainsi qu'in vivo mettant en exergue les effets membranaires de ces acides gras.

Conflits d'intérêts : aucun

\section{Références}

[1] Zakhari S, Li TK. Determinants of alcohol use and abuse : impact of quantity and frequency patterns on liver disease. Hepatology 2007; 46 2032-2039. 
[2] Breitkopf K, Nagy LE, Beier JI, Mueller S, Weng H, Dooley S. Current experimental perspectives on the clinical progression of alcoholic liver disease. Alcohol Clin Exp Res 2009; 33 1647-1655.

[3] Gramenzi A, Caputo F, Biselli M, Kuria F, Loggi E, Andreone P, et al. Review article : alcoholic liver disease - pathophysiological aspects and risk factors. Aliment Pharmacol Ther 2006; 24 1151-1161.

[4] Scaglioni F, Ciccia S, Marino M, Bedogni G, Bellentani S. ASH and NASH. Dig Dis 2011; 29 202-210.

[5] Cohen JI, Nagy LE. Pathogenesis of alcoholic liver disease : interactions between parenchymal and non-parenchymal cells. J Dig Dis 2011; 12 3-9.

[6] Siegmund SV, Dooley S, Brenner DA. Molecular mechanisms of alcohol-induced hepatic fibrosis. Dig Dis 2005; 23 264-274.

[7] Tsukamoto H. Conceptual importance of identifying alcoholic liver disease as a lifestyle disease. J Gastroenterol 2007; 42 603-609.

[8] Stickel F, Hampe J. Genetic determinants of alcoholic liver disease. Gut 2013; 61 $150-159$.

[9] Shukla SD, Pruett SB, Szabo G, Arteel GE. Binge ethanol and liver : new molecular developments. Alcohol Clin Exp Res 2013; 37 550-557.

[10] Day CP, James OF. Steatohepatitis : a tale of two"hits"? Gastroenterology 1998; $114842-845$.

[11] Tsukamoto H, Machida K, Dynnyk A, Mkrtchyan H. "Second hit" models of alcoholic liver disease. Semin Liver Dis 2009; 29 178-187.

[12] Szabo G, Dolganiuc A, Dai Q, Pruett SB. TLR4, ethanol and lipid rafts : a new mechanism of ethanol action with implications for other receptor-mediated effects. $\mathbf{J}$ Immunol 2007; 178 1243-1249. 
[13] Sergent O, Aliche-Djoudi F, Lagadic-Gossmann D. Up-to-date insight about membrane remodeling as a mechanism of action for ethanol-induced liver toxicity. In Shimizu I, ed. Trends in Alcoholic Liver Disease Research - Clinical and Scientific Aspects. InTech; 2012. ISBN: 978-953-307-985-1, DOI: 10.5772/27410. Available from: http://www.intechopen.com/books/trends-in-alcoholic-liver-disease-researchclinical-and-scientific-aspects/up-to-date-insight-about-membrane-remodeling-as-amechanism-of-action-for-ethanol-induced-liver-toxicity.

[14] Shaikh SR, Teague H. N-3 fatty acids and membrane microdomains : from model membrane to lymphocyte function. Prostaglandins Leukot Essent Fatty Acids 2012; 87 205-208.

[15] Rogers KR, Kikawa KD, Mouradian M, Hernandez K, McKinnon KM, Ahwah SM, et al. Docosahexaenoic acid alters epidermal growth factor receptor-related signaling by disrupting its lipid raft association. Carcinogenesis 2010; 31 1523-1530. [16] Cao Q, Mak KM, Lieber CS. Cytochrome P4502E1 primes macrophage to increase TNF-alpha production in response to lipopolysaccharide. Am J Physiol 2005; 289 G95-G107.

[17] Wu D, Cederbaum AI. Oxidative stress and alcoholic liver disease. Semin Liver Dis 2009; 29 141-154.

[18] Albano E. Oxidative mechanisms in the pathogenesis of alcoholic liver disease. Mol Asp Med 2008; 29 9-16.

[19] Greenwel P. Acetaldehyde-mediated collagen regulation in hepatic stellate cells. Alcohol Clin Exp Res 1999; 23 930-933.

[20] Zhu H, Jia Z, Misra H, Li YR. Oxidative stress and redox signaling mechanisms of alcoholic liver disease : updated experimental and clinical evidence. J Dig Dis $2012 ; 13$ 133-142. 
[21] Moriya T, Naito H, Ito Y, Nakajima T. "Hypothesis of seven balances" : molecular mechanisms behind alcoholic liver diseases and association with PPAR $\alpha$. J Occup Health 2009; 51 391-403.

[22] Nordmann R, Ribière C, Rouach H. Implications of free radical mechanisms in ethanol-induced cellular injury. Free Radic Biol Med 1992; 12, 219-240.

[23] Wang HJ, Gao B, Zakhari S, Nagy LE. Inflammation in alcoholic liver disease. Annu Rev Nutr 2012; 32 343-368.

[24] Seki E, Brenner DA. Toll-like receptors and adaptator molecules in liver disease : update. Hepatology 2008; 483 322-335.

[25] De Minicis S, Brenner DA. Oxidative stress in alcoholic liver disease ; role of NADPH oxidase complex. J Gastroenterol Hepatol 2008; 23 S98-S103.

[26] Szabo G, Bala S. Alcoholic liver disease and the gut-liver axis. World J Gastroenterol 2010; 16 1321-1329.

[27] Tuma DJ, Thiele GM, Xu D, Klassen LW, Sorrell MF. Acetaldehyde and malondialdehyde react together to generate distinct protein adducts in the liver during long-term ethanol administration. Hepatology 1996; 23 872-880.

[28] Albano E, Vidali M. Immune mechanisms in alcoholic liver disease. Genes Nutr 2010; 5 141-147.

[29] Duryee MJ, Klassen LW, Freeman TL, Willis MS, Tuma DJ, Thiele GM. Lipopolysaccharide is a cofactor for malondialdehyde-acetaldehyde adduct-mediated cytokine.chemokine release by rat sinusoidal liver endothelial and Kupffer cells. Alcohol Clin Exp Res 2004; 28 1931-1938.

[30] Ambade A, Mandrekar P. Oxidative stress and inflammation : essential partners in alcoholic liver disease. Int $\mathrm{J}$ Hepatol 2012; 2012:853175. doi: $10.1155 / 2012 / 853175$. 
[31] Vidali M, Stewart SF, Albano E. Interplay between oxidative stress and immunity in the progression of alcohol-mediated liver injury. Trends Mol Med 2007; $1463-71$

[32] Friedman SL. Mechanisms of hepatic fibrogenesis. Gastroenterology 2008; 134 1655-1669.

[33] Seth D, D'Souza El-Guindy NB, Apte M, Mari M, Dooley S, Neuman M, et al. Alcohol, signaling and ECM turnover. Alcohol Clin Exp Res 2010; 34 4-18.

[34] Gao B, Bataller R. Alcoholic liver disease : pathogenesis and new therapeutic targets. Gastroenterology 2011; 141 1572-1585.

[35] Gao B, Seki E, Brenner DA, Friedman S, Cohen JI, Nagy L, et al. Innate immunity in alcoholic liver disease. Am J Physiol 2011; 300 G516-G525.

[36] Simons K, Toomre D. Lipid rafts and signal transduction. Nature reviews. Molec Cell Biol 2000; 1 31-39.

[37] Lingwood D, Simons K. Lipid rafts as a membrane-organizing principle. Science 2010; 237 46-50.

[38] Moffet S, Brown DA, Linder ME. Lipid-dependent targeting of G proteins into rafts. J Biol Chem 2000; 275 2191-2198.

[39] Mumby SM. Reversible palmitoylation of signaling proteins. Curr Opin Cell Biol 1997; 9 148-154.

[40] Schmitz G, Orso E. CD14 signaling in lipid rafts : new ligands and co-receptors. Current Opin Lipid 2002; 13, 513-521.

[41] Pike LJ. Lipid rafts : bringing order to chaos. J Lipid Res 2003; 44, 655-667.

[42] Harder T, Engelhardt KR. Membrane microdomains in lymphocytes - from lipid rafts to protein scaffolds. Traffic 2004; 5 265-275. 
[43] Triantafilou M, Miyake K, Golenbock DT, Triantafilou K. Mediators of innate immune recognition of bacteria concentrate in lipid rafts and facilitate lipopolysaccharide-induced cell activation. J Cell Sci 2002; 115 2603-2611.

[44] Fitzgerald KA, Rowe RC, Golenbock DT. Endotoxin recognition and signal transduction by the TLR4/MD2-complex. Microbes Infect 2004; 6 1361-1367.

[45] Dolganiuc A, Bakis G, Kodys K, Mandrekar P, Szabo G. Acute ethanol treatment modulates Toll-like receptor-4 association with lipid rafts. Alcohol Clin Exp Res 2006; 30 76-85.

[46] Dai Q, Zhang J, Pruett SB. Ethanol alters cellular activation and CD14 partitioning in lipid rafts. Biochem Biophys Res Commun 2005; 332 37-42.

[47] Fernandez-Lizarbe S, Pascual M, Gascon MS, Blanco A, Guerri C. Lipid rafts regulate ethanol-induced activation of TLR4 signaling in murine macrophages. Mol Immunol 2008; 45 2007-2016.

[48] Roach DR, Bean AG, Demangel C, France MP, Briscoe H, Britton WJ. TNF regulates chemokine induction essential for cell recruitment, granuloma formation, and clearance of mycobacterial infection. J Immunol 2002; 168 4620-4627.

[49] Ali T, Kaitha S, Mahmood S, Ftesi A, Stone J, Bronze MS. Clinical use of antiTNF therapy and increased risk of infections. Drug Healthc Patient Saf 2013; 5 7999.

[50] Nourissat P, Travert M, Chevanne M, Tekpli X, Rebillard A, Le Moigne-Müller $\mathrm{G}$ et al. Ethanol induces oxidative stress in primary rat hepatocytes through the early involvement of lipid raft clustering. Hepatology 2008; 47 59-70.

[51] Aliche-Djoudi F, Podechard N, Chevanne M, Nourissat P, Catheline D, Legrand $P$ et al. Physical and chemical modulation of lipid rafts by a dietary n-3 
polyunsaturated fatty acid increases ethanol-induced oxidative stress. Free Radic Biol Med 2011; 51 2018-2030.

[52] Valenzuela R, Espinoza A, Gonzalez-Manan D, D'Espesssailles A, Fernandez V, Videla LA et al. N-3 long-chain polyunsaturated fatty acid supplementation significantly reduces liver oxidative stress in high fat induced steatosis. Plos one 2012; 7 e46400.

[53] Di Minno MND, Russolillo A, Lupoli R, Ambrosinao P, Di Minno A, Tarantino G. Omega-3 fatty acids for the treatment of non-alcoholic fatty liver disease. World $\mathbf{J}$ Gastroenterol 2012; 18 5839-5847.

[54] Valenzuela R, Videla LA. The importance of the long-chain polyunsaturated fatty acid n-6/n-3 ratio in development of non-alcoholic fatty liver associated with obesity. Food Funct 2011; 2 644-648.

[55] Parker HM, Johnson NA, Burdon CA, Cohn JS, O'Connor HT, George J. Omega-3 supplementation and non-alcoholic fatty liver disease : a systematic review and meta-analysis. J Hepatol 2012; 56 944-951.

[56] Nanji AA, French SW. Dietary factors and alcoholic cirrhosis. Alcohol Clin Exp Res 1986; 10 271-273.

[57] Nanji AA, Mendenhall CL, French SW. Beef fat prevents alcoholic liver disease in the rat. Alcohol Clin Exp Res 1989; 13 15-19.

[58] Nanji AA, Khwaja S, tahan SR, Sadrzadeh SMH. Plasma levels of a novel noncyclooxygenase-derived prostanoid (8-isoprostane) correlate with severity of liver injury in experimental alcoholic liver disease. J Pharmacol Exp Ther 1994; 269, 1280-1285.

[59] Nanji AA, Zhao S, Sadrzadeh SM, Danneberg AJ, Tahan SR, Waxman DJ. Markedly enhanced cytochrome P450 2E1 induction and lipid peroxidation is 
associated with severe liver injury in fish oil-ethanol-fed rats. Alcohol Clin Exp Res 1994; 18 1280-1285.

[60] Nanji AA, Dannenberg AJ, Jokelainen K, Bass NM. Alcoholic liver injury in the rat is associated with reduced expression of peroxisome proliferator- $\alpha$ (PPAR $\alpha$ )regulated genes and is ameliorated by PPAR $\alpha$ activation. J Pharmacol Exp Ther $2004 ; 310417-424$.

[61] Polavarapu R, Spitz DR, Sim JE, Follansbee MH, Oberley LW, Rahemtulla A, et al. Increased lipid peroxidation and impaired antioxidant enzyme function is associated with pathological liber injury in experimental alcoholic liver disease in rats fed diets high in corn oil and fish oil. Hepatology 1998; 27 1317-1323.

[62] Donohue TM, Kharbanda KK, Casey CA, Nanji AA. Decreased proteasome acitivty is associated with increased severity of liver pathology and oxidative stress in experimental alcoholic liver disease. Alcohol Clin Exp Res 2004; 28 1257-1263.

[63] Nieto N. Ethanol and fish oil induce NFkappaB transactivation of the collagen alpha2(I) promoter through lipid peroxidation-driven activation of the PKC-PI3KAkt pathway. Hepatology 2007; 45 1433-1445.

[64] Nanji AA, Griniuvuene B, Sadrzadeh SM, Levitsky S, McCully JD. Effect of type of dietary fat and ethanol on antioxidant enzyme mRNA induction in rat liver. $\mathrm{J}$ Lipid Res 1995; 36 736-744.

[65] Su GL, Rahemtulla A, Thomas P, Klein RD, Wang SC, Nanji AA. CD14 and lipopolysaccharide binding protein expression in a rat model of alcoholic liver disease. Am J Pathol 1998; 152 841-849.

[66] Nanji AA, Jokelainen K, Rahemtulla A, Miao L, Fogt F, Matsumoto H, et al. Activation of nuclear factor kappa B and cytokine imbalance in experimental alcoholic liver disease in the rat. Hepatology 1999; 30 934-943. 
[67] Nanji AA, Miao L, Thomas P, Rahemtulla A, Khwaja S, Zhao S, et al. Enhanced cyclooxygenase-2 gene expression in alcoholic liver disease in the rat. Gastroenterology 1997; 112 943-951.

[68] Wada S, Yamazaki T, Kawano Y, Miura S, Ezaki O. Fish oil fed prior to ethanol administration prevents acute ethanol-induced fatty liver in mice. J Hepatol 2008; 49 441-450.

[69] Song BJ, Moon KH, Olsson NU, Salem N. Prevention of alcoholic fatty liver and mitochondrial dysfunction in the rat by long-chain polyunsaturated fatty acids. J Hepatol 2008; 49 262-273.

[70] Huang LL, Wan JB, Wang B, He CW, Ma H, Li TW, et al. Suppression of acute ethanol-induced hepatic steatosis by docosahexaenoic acid is associated with downregulation of stearoyl-CoA desaturase 1 and inflammatory cytokines. Prostaglandins Leukot Essent Fatty Acids 2013; 88 347-353.

[71] Tarahosky YS, Muzafarov EN, Kim YA. Rafts making and rafts braking: how plant flavonoids may control membrane heterogeneity. Mol. Cell. Biochem 2008; $31465-71$.

[72] Wassal SR, Stillwell W. Polyunsaturated fatty-acid-cholesterol interactions: domain formation in membranes. Biochim Biophys Acta 2009; 1788 24-32.

[73] Kubo K, Saito M, Tadokoro T, Maekawa A. Dietary docosahexaenoic acid dose not promote lipid peroxidation in rat tissue to the extent expected from peroxidizability index of the lipids. Biosci Biotechnol Biochem 1998; 62 1698-1706. [74] Song JH, Fujimoto K, Miyazawa T. Polyunsaturated (n-3) fatty acids susceptible to peroxidation are increase in plasma and tissue lipids of rats fed docosahexaenoic acid-containing oil. J. Nutr 2000; 130 3028-3033. 
[75] Diaz O, Berquand A, Dubois M, Di Agostino S, Sette C, Bourgoin et al. The mechanism of docosahexaenoic aci-induced phospholipase D activation in human lymphocytes involves exclusion of the enzyme from lipid rafts. J Biol Chem 2002; $27739368-39378$.

[76] Li Q, Tan L, Wang C, Li N, Li Y, Xu G, et al. Polyunsaturated eicosapentaenoic acid changes lipid composition in lipid rafts. Eur J Nutr 2006; 45 144-151.

[77] Chen W, Jump DB, Esselman WJ, Busik JV. Inhibition of cytokine signaling in human retinal endothelial cells through modification of caveolae/lipid rafts by docosahexaenoic acid. Invest Ophtalmol Vis Sci 2007; 48 18-26.

[78] Wong SW, Kwon MJ, Choi AMK, Kim HP, Nakahira K, Hwang DH. Fatty acids modulate toll-like receptor 4 activation through regulation of receptor dimerization and recruitment into lipid rafts in a reactive oxygen species-dependent manner. J Biol Chem 2009; 284 27384-27392.

[79] Fan YY, Ly LH, Barhoumi R, McMurray DN, Chapkin RS. Dietary docosahexaenoic acid suppresses $\mathrm{T}$ cell protein kinase $\mathrm{Ct}$ lipid raft recruitment and IL-2 production. J Immunol 2004; 173 6151-6160.

[80] Rockett BD, Teague H, Harris M, Melton M, Williams J, Wassall SR et al. Fish oil increases raft size and membrane order of B cells accompanied by differential effects on function. J Lipid Res 2012; 53 674-685.

[81] Kim K, Jung N, Lee K, Choi J, Kim S, Jun J, et al. Dietary omega-3 polyunsaturated fatty acids attenuate hepatic ischemia-reperfusion injury in rats by modulating toll-like receptor recruitment into lipid rafts. Clin Nutr 2013; in press.

[82] Gurzell EA, Teague H, Harris M, Clinthorne J, Shaikh SR, Fenton JI. DHAenriched fish oil targets B cell lipid microdomains and enhances ex vivo and in vivo B cell function. J Leukoc Biol 2013; 93 463-470. 
[83] Shaikh SR, Dumaual AC, Castillo A, LoCascio D, Siddiqui RA, Stillwell W, et al. Oleic and docosahexaenoic acid differentially phase separate from lipid raft molecules : a comparative NMR, DSC, AFM and detergent extraction study. Biophys J 2004; 87 1752-1766.

[84] Shaikh SR, Rockett BD, Salameh M, Carraway K. Docosahexaenoic acid modifies the clustering and size of lipid rafts and the lateral organization and surface expression of MHC class I of ELA cells. J Nutr 2009; 139 1632-1639.

[85] Rockett BD, Franklin A, Harris M, Teague H, Rockett A, Shaikh SR. Membrane raft organization is more sensitive to disruption by (n-3) PUFA than nonraft organization in EL4 and B cells. J Nutr 2011; 141 1041-1048.

[86] Shaikh SR. Diet-induced docosahexaenoic acid non-raft domains and lymphocyte function. Prostaglandins Leukot Essent Fatty Acids 2010; 82 159-164.

[87] Williams JA, Batten SE, Harris M, Rockett BD, Shaikh SR, Stillwell W et al. Docosahexaenoic and eicosapentaenoic acids segregate differently between raft and nonraft domains. Biophys J 2012; 103 228-237.

[88] Aliche-Djoudi F, Podechard N, Collin A, Chevanne M, Provost E, Poul M, Le Hégarat L, Catheline D, Legrand P, Dimanche-Boitrel M-T, Lagadic-Gossmann D, Sergent O. A role for lipid rafts in the protection afforded by docosahexaenoic acid against ethanol toxicity in primary rat hepatocytes. Food Chem Toxicol 2013; 60 286-296.

\section{Legendes des figures}




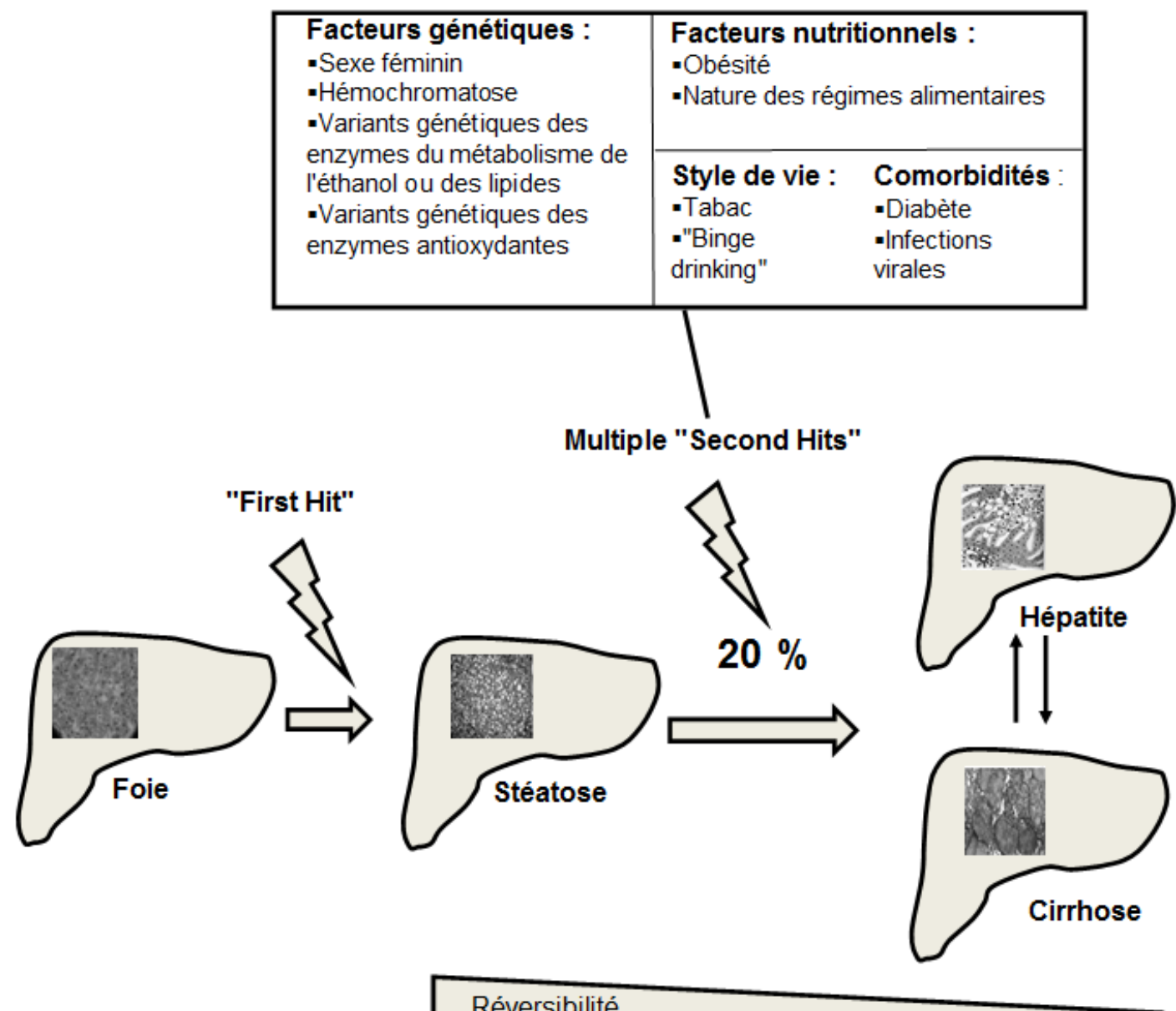

Réversibilité

Figure 1. Progression de la maladie alcoolique du foie chez les buveurs excessifs d'alcool. 


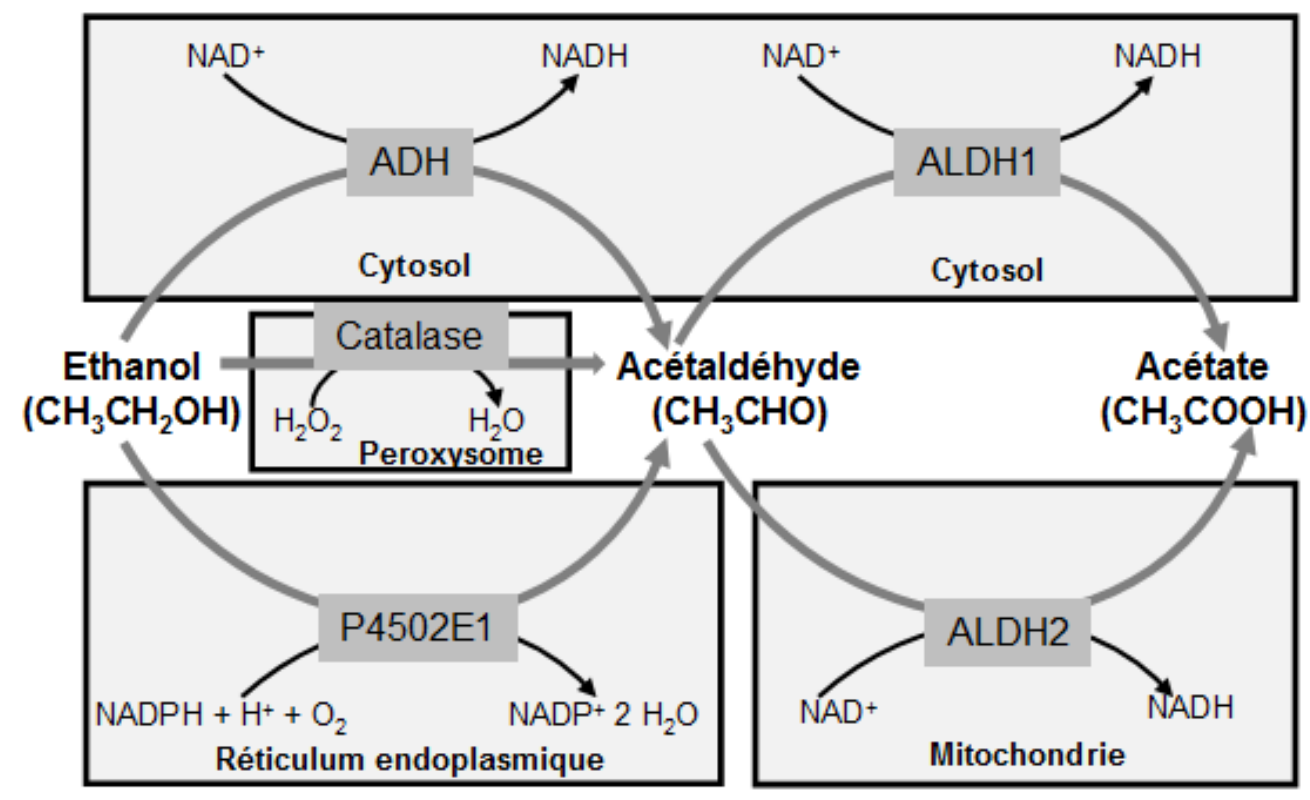

Figure 2. Principales voies du métabolisme de l'éthanol dans le foie. ADH : Alcool déshydrogénase ; ALDH : aldéhyde déshydrogénase ; P4502E1 : cytochrome P4502E1 ; NAD : nicotinamide adénine dinucléotide ; NADH : nicotinamide adénine dinucléotide réduit. 


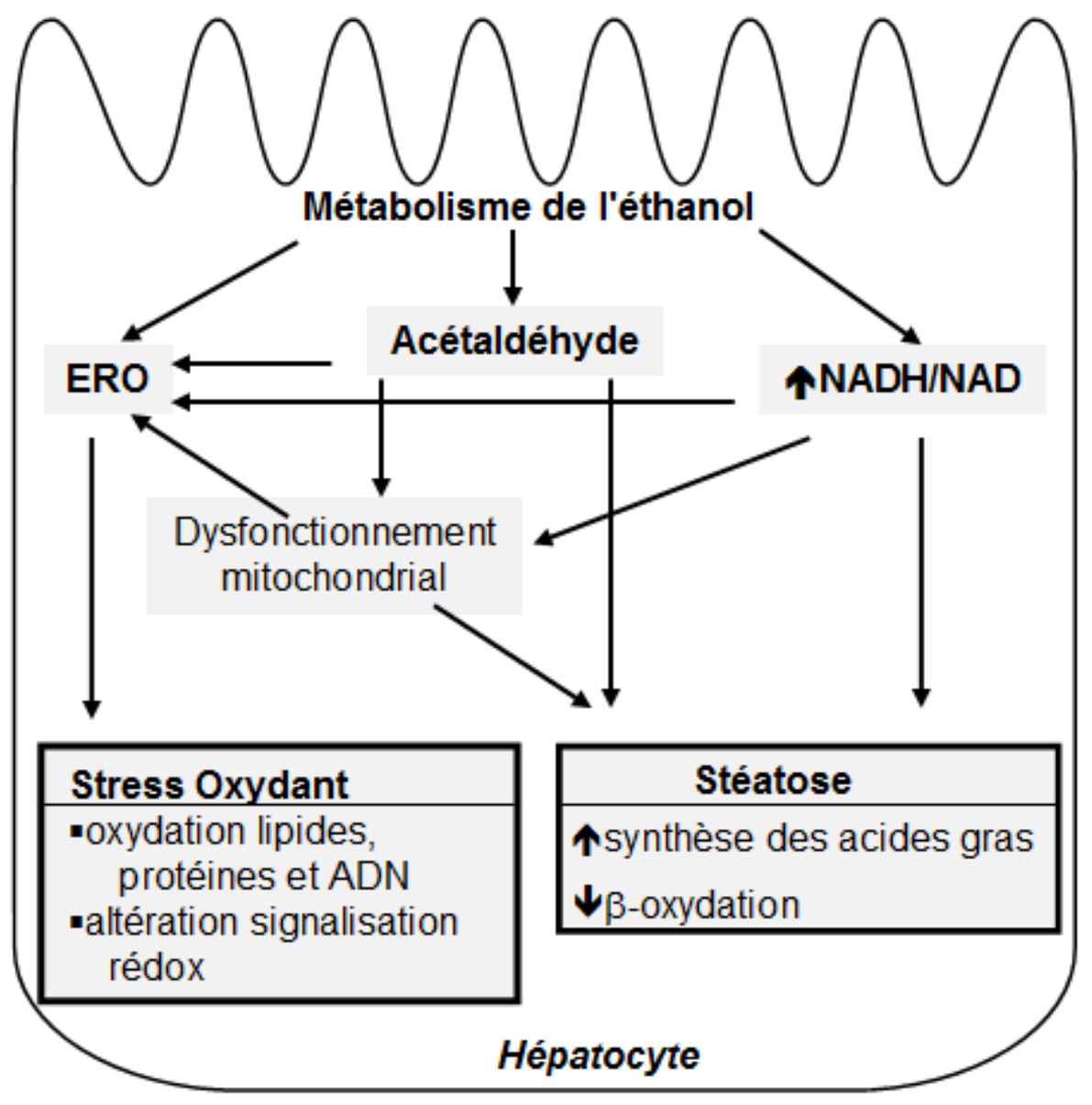

Figure 3. Contribution du métabolisme de l'éthanol à l'induction du stress oxydant et de la stéatose dans l'hépatocyte. ERO : espèces réactives de l'oxygène. 


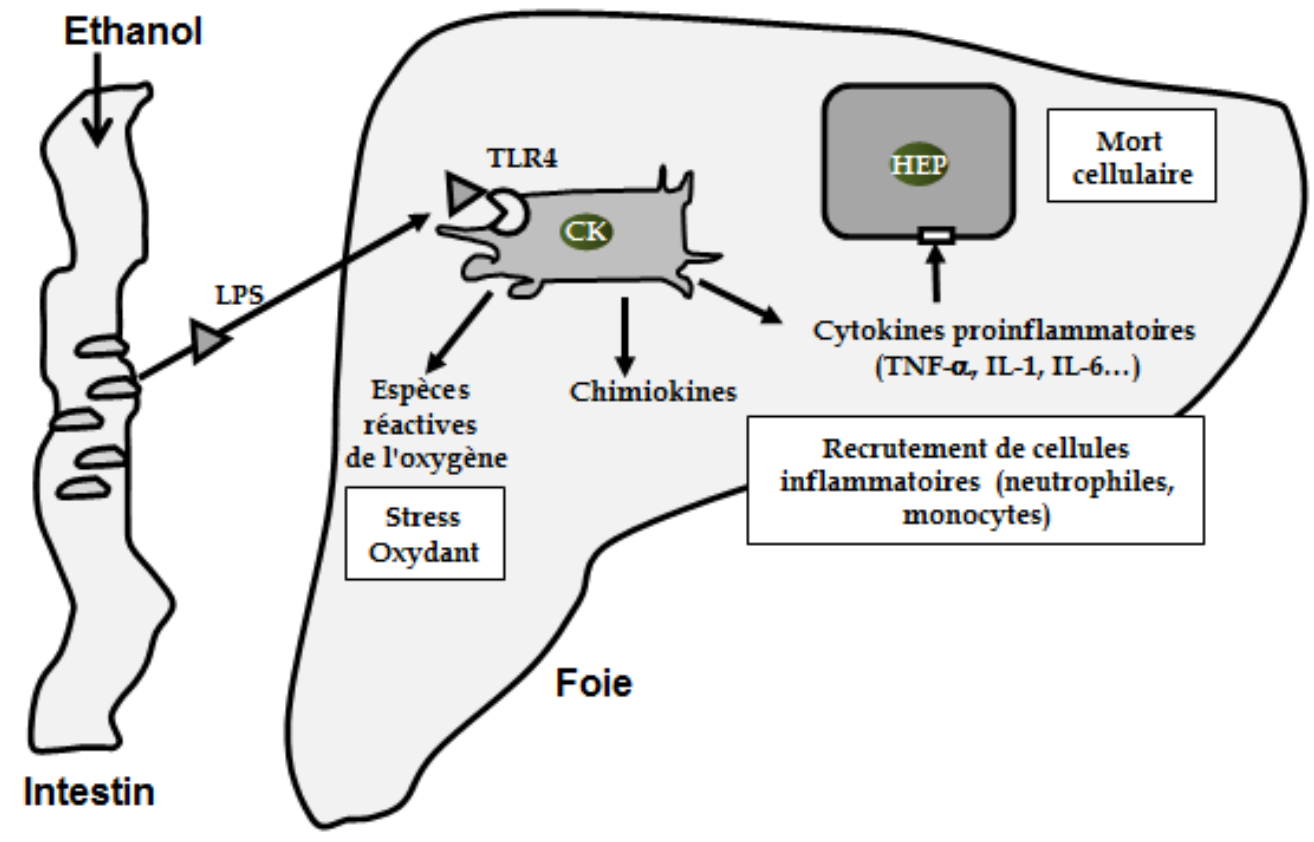

Figure 4. Promotion de l'inflammation et de la mort cellulaire suite à l'activation de voies de signalisation par le lipopolysaccharide. CK : cellule de Küpffer ; HEP : hepatocyte, LPS : lipopolysaccharide ; IL-1 : interleukine 1 ; IL-6 : interleukine 6 ; TNF $\alpha$ : tumor necrosis factor alpha. 


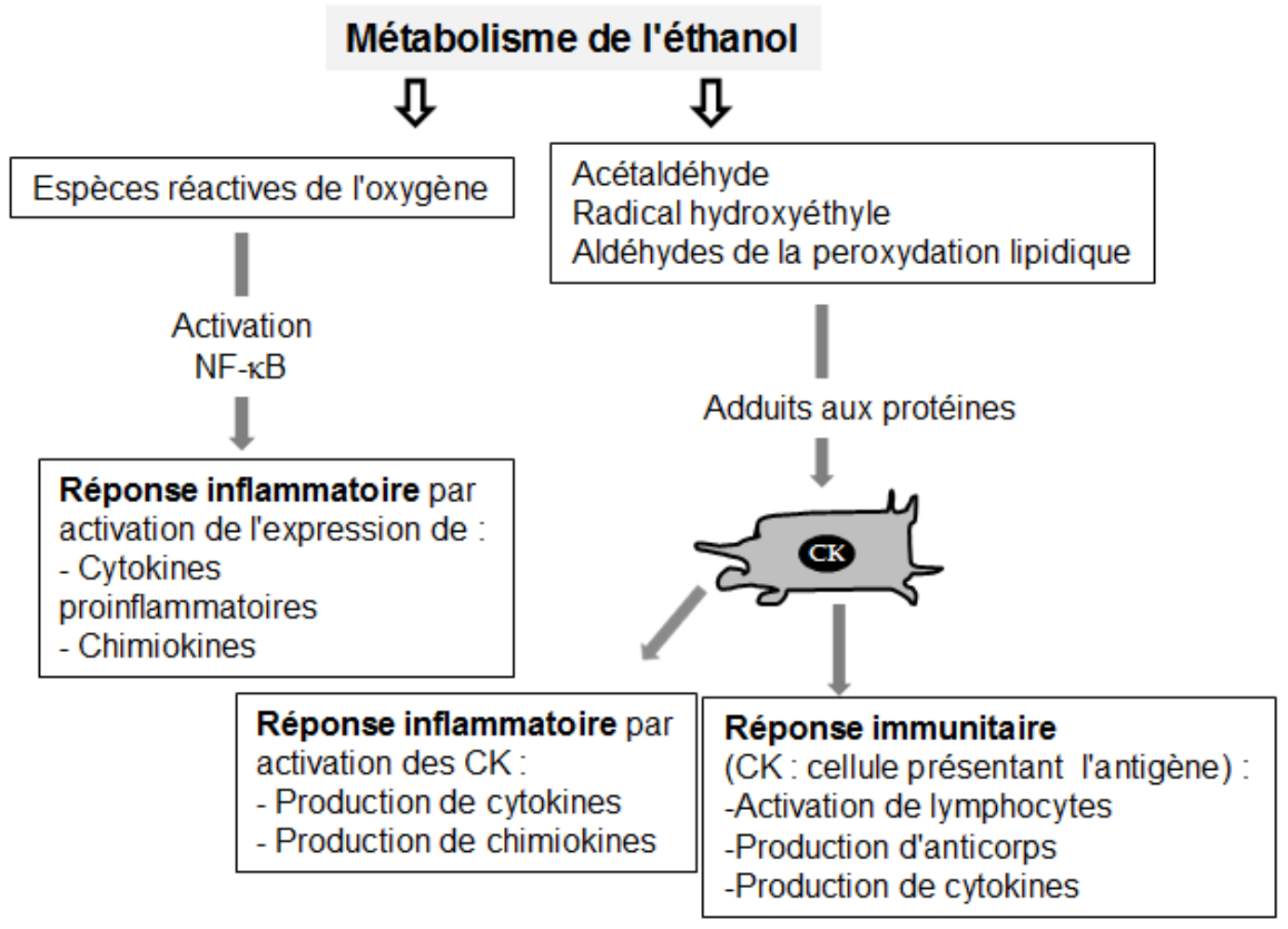

Figure 5. Rôle des produits du métabolisme de l'éthanol dans le développement de l'inflammation. CK : cellule de Küpffer. 

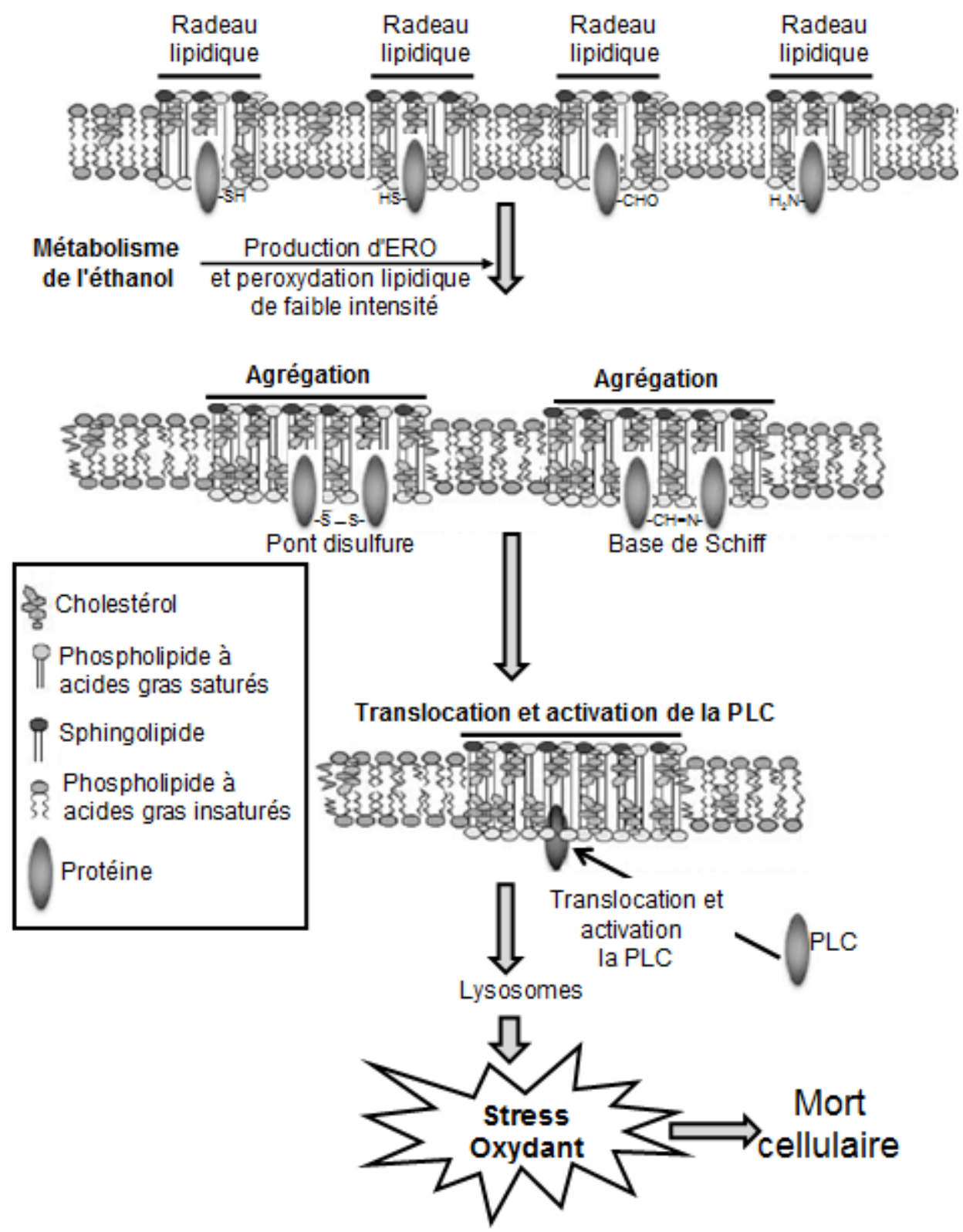

Figure 6. Implication des radeaux lipidiques dans le stress oxydant et la mort cellulaire induits par l'éthanol. ERO : espèces réactives de l'oxygène ; PLC : phospholipase C. 


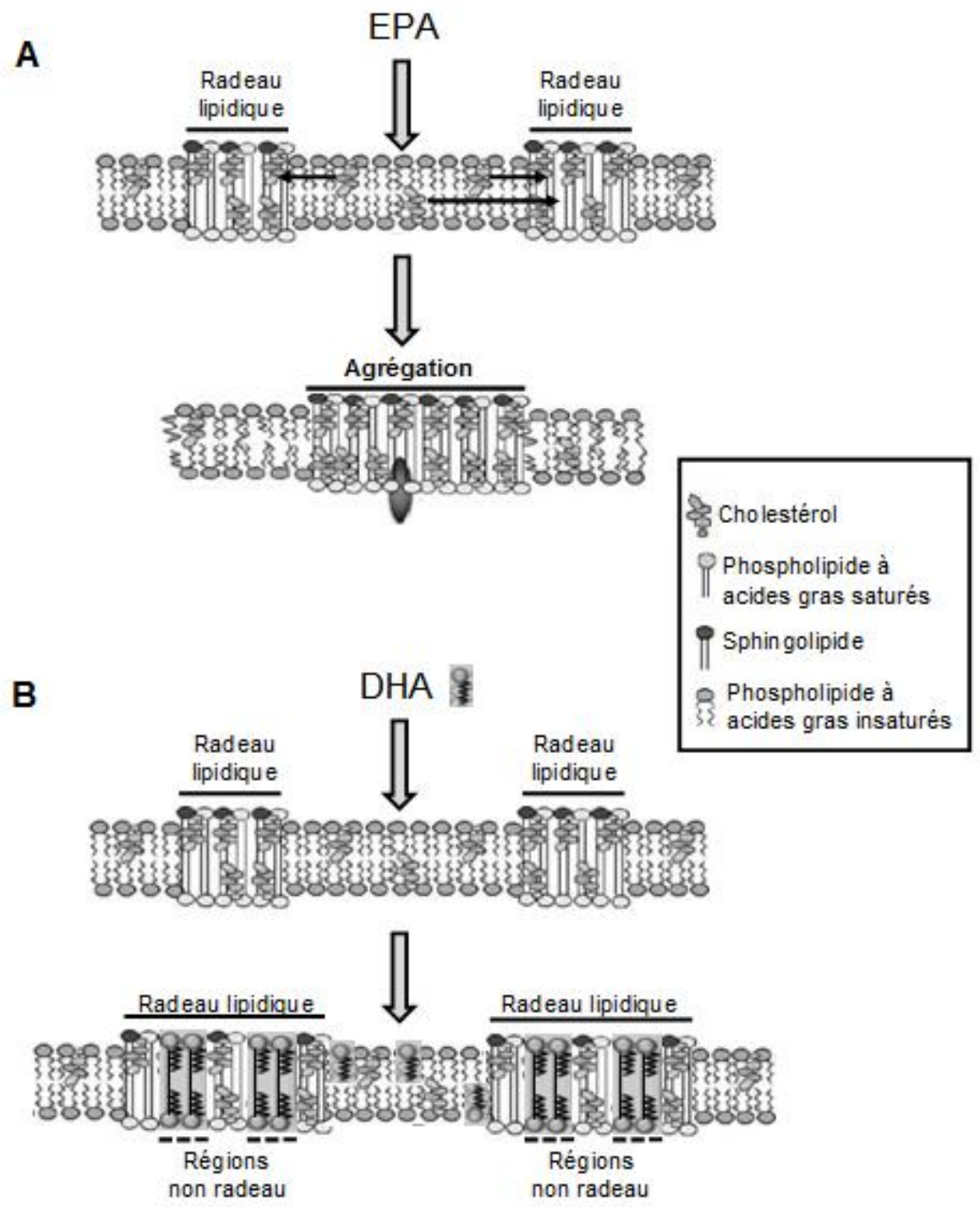

Figure 7. Effet différentiel des acides gras polyinsaturés oméga 3 (EPA et DHA) sur les propriétés physicochimiques des radeaux lipidiques. DHA : acide docosahexaénoique ; EPA : acide eicosapentaénoique. 